\title{
Ecoenogastronomia - sustentabilidade e resgate cultural na produção de vinhos na Serra Gaúcha, Brasil
}

\author{
Ecoenogastronomy - sustainability and cultural rescue in the production of wines in Serra Gaúcha, \\ Brazil
}

\author{
Roberta Giraldi Romano
}

Carlos Alberto Cioce Sampaio

Manon Garcia

Pontifícia Universidade Católica do Paraná - Paraná - Curitiba - Brasil

Gabriela Schäfer

Universidade de Caxias do Sul - UCS - Caxias do Sul - Rio Grande do Sul - Brasil

\begin{abstract}
Resumo: Com a evidência da crise ambiental e a necessidade de repensar os modelos de produção alimentar, emergem iniciativas de promoção da sustentabilidade em diversos setores, dentre eles o vitivinícola. O vinho é parte importante da cultura gastronômica brasileira, principalmente na Serra Gaúcha, região de colonização italiana e maior produtora de vinhos do país. Partindo do conceito de ecogastronomia, o presente trabalho dedica-se a analisar a relação entre sustentabilidade e resgate cultural na produção de vinhos no Brasil. Com a revisão da literatura, mapeamento e contato com vinícolas artesanais da Serra Gaúcha, é possível afirmar que há estreita relação entre as práticas de sustentabilidade e de resgate cultural nas produções artesanais em pequena escala. São experiências que promovem o vinho bom, justo e limpo, além de estarem ecologicamente incorporadas, valorizando a biocultura local e os ritmos naturais.
\end{abstract}

Palavras-chave: Sustentabilidade. Resgate Cultural. Vinho.

\begin{abstract}
With the evidence of the environmental crisis and the need to rethink the food production models, initiatives to promote sustainability emerge in several sectors, including winemaking. Wine is an important part of the Brazilian gastronomic culture, especially in the Serra Gaúcha, an area of Italian colonization and the country's largest wine producer. Starting from the concept of ecogastronomy, the present work is dedicated to analyzing the relationship between sustainability and cultural rescue in the production of wines in Brazil. With the literature review, mapping and contact with artisanal wineries of the Serra Gaúcha, it is possible to affirm that there is a close relationship between sustainability practices and cultural rescue in small scale artisanal productions. These are experiences that promote good, fair and clean wine, as well as being ecologically incorporated, valuing local bio-culture and natural rhythms.
\end{abstract}

Keywords: Sustainability. Cultural Rescue. Wine. 


\section{INTRODUÇÃO}

A produção de vinhos no Brasil se iniciou com os colonizadores portugueses, com videiras da llha da Madeira em 1532, mas foram os imigrantes italianos que a tornaram importante cultural e economicamente no final do século XIX, principalmente no Rio Grande do Sul. Em um primeiro momento foi a varietal americana Isabel (híbrida de Vitis vinífera e Vitis labrusca) a principal casta cultivada, posteriormente, com maior conhecimento sobre as características de solo e clima, foram introduzidas castas viníferas europeias. A história do vinho no Brasil é perpassada pela cultura dos imigrantes europeus, que trouxeram a experiência e a arte de elaborar vinhos e até hoje influenciam pequenas e grandes vinícolas (TERUCHKIN, 2003).

Para Harvey (2003), o consumo de vinhos pode ser considerado "capital cultural", está ligado à cozinha regional, incorporado às práticas que transformam a regionalidade em estilo de vida marcado por estruturas distintas de sentimento. Não obstante, apesar da valorização do vinho elaborado com variedades europeias (vinho fino) em detrimento do vinho produzido com variedades americanas ou híbridas (vinho de mesa), este último mantém clientela cativa no Brasil, devido a aspectos culturais relacionados à imigração e à ancestralidade, fazendo com que a produção artesanal $^{1}$ conviva com a produção industrial (SOUZA, OTANI, VERDI, 2010).

Santos (2011) considera que os hábitos alimentares são resultado de uma narrativa da memória social de uma comunidade; são mutáveis, acompanharam e acompanham os distintos ritmos da história. Através do estudo da gastronomia é possível conhecer não apenas a "arte de cozinhar" e o "prazer de comer", mas também a sua relação com os recursos alimentares disponíveis. O estudo da alimentação é um elemento para o entendimento da sociedade e de seu desenvolvimento (ABREU et al., 2001).

Atualmente, o modelo de abastecimento alimentar é globalizado, busca a padronização de

\footnotetext{
${ }^{1}$ Entendida como a produção de pequena escala que
} utiliza técnicas artesanais na elaboração de vinhos. produção, processamento, comercialização, consumo e acesso - este modelo possui impacto socioambiental e desprestigia a cultura alimentar local (GÓES, 2010). Ribeiro, Jaime e Ventura (2017) consideram que a preocupação com formas mais sustentáveis e saudáveis de se produzir alimentos tem motivado alertas da comunidade científica há décadas, citando a obra Silent Spring em 1962, de Rachel Carson, crítica ao uso massivo de pesticidas, e Diet for a Small Planet em 1971, de Frances Lappé, que discute o impacto da dieta humana na segurança alimentar e na sustentabilidade planetária.

Alinhados à necessidade de repensar este modelo, emergem movimentos, como o Slow Food, que entende que alimentar-se é um ato agrário e gastronômico e o alimento deve atender três requisitos: ser bom, limpo e justo. Nas palavras de seu fundador 2: "as coisas boas são direito de todos". Deste movimento surge o conceito de ecogastronomia, que congrega "a ética e o prazer da alimentação, apoiando um modelo de agricultura menos intensivo, mais saudável, sustentável e que valorize o conhecimento de comunidades locais" (SLOW FOOD BRASIL, 2018, não p.).

O vinho é parte importante da cultura gastronômica brasileira e, inserido em um contexto global de busca pela sustentabilidade, seu setor almeja se adequar às exigências atuais da sociedade: cresce a preocupação com a qualidade nutricional alimentar e, consequentemente, a saúde, fazendo com que produtores procurem modos mais saudáveis - para o ser humano e para o meio ambiente - de produzir o vinho, seja no manejo das uvas com o cultivo orgânico ou pela forma de vinificação, ao deixar de utilizar aditivos químicos em seu processo.

Neste contexto, o presente artigo pretende analisar a relação entre sustentabilidade e resgate cultural na produção de vinhos no Brasil, a partir da perspectiva da ecogastronomia.

\section{Metodologia}

${ }^{2}$ Carlo Petrini, jornalista, escritor, presidente e fundador do movimento Slow Food. 
Para atender ao objetivo proposto realizou-se uma pesquisa bibliométrica que incluiu os termos "ecogastronomia" (3 resultados), "ecogastronomy" (4 resultados), "slow food" + "vinho" (3 resultados), "slow food"+ "wine" (282 resultados), "vinho sustentável" (0 resultados), "sustainable wine" (128 resultados) no Portal de Periódicos da Capes, composto por mais de 45 mil publicações periódicas, internacionais e nacionais. A pesquisa foi limitada a artigos, publicados entre 2010 e 2018, somente obras revisadas por pares. Pela leitura dos títulos foram selecionados os artigos com maior aderência ao tema, resultando na leitura completa de vinte e oito artigos, dos quais vinte sustentam a revisão da literatura e estado da arte junto a outras obras de relevância.

O recorte de estudo adotado para a pesquisa empírica foi a Serra Gaúcha, Rio Grande do Sul, Brasil, por sua importância história e representatividade econômica no setor. Por meio de busca documental em buscadores online e contato com produtores, foram mapeadas as iniciativas de produção vinícola alinhadas à sustentabilidade e resgate cultural. Para a análise, foram consideradas as vinícolas artesanais de pequena produção, visto que a literatura indica a predominância da cultura de mercado nas grandes empresas do setor.

\section{Revisão da literatura}

\subsection{Sustentabilidade no setor vinícola}

Atualmente, o consumidor tem incorporado novos aspectos em seu estilo de vida e, consequentemente, em suas escolhas, considerando quão bem os produtos satisfazem suas necessidades e como estes afetam meio ambiente. À medida que a consciência do consumidor cresce, o mercado deve observar também a crescente aceitação e demanda por vinhos sustentáveis, proporcionando às vinícolas que acompanhem esta tendência: destaque em relação a seus concorrentes, oportunidades de eficiência e redução de custos e ganhos de reputação (BARBER, TAYLOR, STRICK, 2009; SZOLNOI, 2013). A disseminação de iniciativas de sustentabilidade é oportunidade para um crescimento equilibrado e de longo prazo neste setor, mas em estudo realizado com quarenta e cinco produtores dos Estados Unidos, França, Espanha, Itália, Alemanha, Hungria e Grécia, identificou-se que muitos possuem uma visão limitada de "sustentabilidade", associando-a somente a gestão de resíduos, por exemplo (SZOLNOI, 2013; POMARICI, VECHIO, 2014; MERLI, PREZIOSI, ACAMPORA, 2018).

O cultivo de uvas e a produção de vinho estão associados a inúmeros aspectos ambientais, como o uso do solo, água, energia, produtos químicos, a geração e o gerenciamento de resíduos orgânicos e inorgânicos, emissões de gases de efeito estufa, o impacto nos ecossistemas, etc. Tratam-se de temas em voga na sociedade, um desafio universal contemporâneo, motivados pela crise ambiental e a necessidade de repensar modelos de produção ainda inexplorados na produção de vinhos (CHRIST, BURRIT, 2013; MERLI, PREZIOSI, ACAMPORA, 2018).

Embora existam casos de referência, dados sobre as implicações ambientais do setor vinícola são esparsos, sendo necessário um esforço de pesquisa que investigue práticas e informações que subsidiem soluções, buscando estabelecer uma referência para o comprometimento com uma produção de vinho mais saudável, para o ser humano e para o meio ambiente (CHRIST, BURRIT, 2013).

Para Mariani e Vastola (2015) há um consenso de que as práticas sustentáveis, ainda que privilegiem as dimensões ambiental e social, não deixam de ter viabilidade econômica, havendo a necessidade de identificar benefícios e custos envolvidos na produção sustentável. Além disso, urge melhorar o entendimento e uso de rótulos e reivindicações sustentáveis, aumentando o envolvimento dos consumidores e sua atitude em relação ao vinho sustentável. Montella (2017) aponta que os consumidores estão tomando consciência cada vez mais frequente sobre as consequências 
ambientais de suas escolhas; em seu estudo, a autora identificou que visitantes que buscam o turismo de vinho sustentável, na maioria dos casos, não são turistas de vinho, mas buscam uma experiência de sustentabilidade.

Em todo o mundo a indústria do vinho é composta por um grande número de pequenas $\mathrm{e}$ médias empresas operando em contextos naturais e sociais distintos. Para as vinícolas artesanais, a sustentabilidade muitas vezes é uma filosofia, um estilo de vida, ainda que entre os produtores a viticultura seja mais popular que a enologia em relação às técnicas sustentáveis (SZOLNOKI, 2013; MARIANI, VASTOLA, 2015).

São expoentes do setor vinícola sustentável os termos "produção sustentável", "produção orgânica" e "produção biodinâmica", sendo a primeira mais flexível e a segunda e terceira as que requerem maior comprometimento por suas regras e restrições. Frequentemente a produção sustentável é mais abrangente e pode englobar também estas práticas agrícolas (SZOLNOKI, 2013).

Christ e Burrit (2013) destacam que muitos confundem estes termos; há falta de informação generalizada entre organizações, produtores e consumidores e superar estas barreiras no fluxo de informação pode um desafio para prospectar o futuro do vinho sustentável. Há dificuldade no estabelecimento deste mercado, como apontam Schäufele e Hamm (2018) sobre os orgânicos: falta confiança na rotulagem, na qualidade do vinho orgânico e desconhecimento sobre as práticas de produção.

O vinho orgânico é produzido com uvas de agricultura orgânica, também conhecida como agricultura biológica na Europa, prioriza o não uso de insumos químicos (fertilizantes sintéticos, pesticidas, herbicidas, etc.), mas algumas substâncias são permitidas, de acordo com a legislação local e órgãos de certificação. O vinho biodinâmico é produzido com

\footnotetext{
${ }^{3}$ Aqui tratada enquanto prática agrícola e cultural.

4 Autoavaliação, pegada, protocolos, guias e certificações.
}

uvas da agricultura biodinâmica ${ }^{3}$, entendida como uma combinação de práticas agrícolas "dinâmicas", sem o uso de insumos químicos ou sementes geneticamente modificadas, utilizando preparações e caldas para o manejo. As práticas "dinâmicas" visam influenciar aspectos biológicos e metafísicos da vinha, como aumentar a força vital ou adaptá-la aos ritmos naturais, utilizando o plantio de acordo com as fases lunares, por exemplo (SZOLNOKI, 2013).

Para a International Organization of Vine and Wine (2004, p. 2) a vitivinicultura sustentável é definida como:

\begin{abstract}
Estratégia global na escala dos sistemas de produção e processamento da uva, incorporando ao mesmo tempo a sustentabilidade econômica de estruturas e territórios, produzindo produtos de qualidade, considerando requisitos de precisão em viticultura sustentável, riscos ao meio ambiente, segurança de produtos e saúde do consumidor e valorização dos aspectos patrimoniais, históricos, culturais, ecológicos e paisagísticos.
\end{abstract}

Flores (2018) aponta cinco categorias ${ }^{4}$ como estruturas da sustentabilidade no setor vinícola, dentre elas a autoavaliação ${ }^{5}$, entendida como normas voluntárias que estabelecem diretrizes e indicadores a fim de fornecer conhecimento da situação atual para planejar ações futuras.

\subsection{Vinho sustentável e cultura alimentar}

Biologicamente, as pessoas se enfadam de se alimentarem homogeneamente, isto é, sem diversidade regular. Desta forma, a eficiência não pode ser o único objetivo da produção. Observa-se recentemente que, ao invés de haver uma convergência para um padrão industrial uniforme de altas calorias e sabores fortes, as pessoas recorrem a diversidade, história e valores geográficos

\footnotetext{
${ }^{5}$ Em caráter metodológico, esta categoria foi utilizada para a seleção dos casos analisados. Entende-se que a autoavaliação representa um primeiro estágio nas estruturas de sustentabilidade, sendo incorporado nas outras quatro.
} 
incorporados em alimentos étnicos tradicionais (KWON, 2017).

A evolução da ciência aplicada aos alimentos conduziu a sociedade ao que se entende, atualmente, por cultura alimentar, ou seja, ela está baseada nas formas encontradas de proteger o alimento de animais e da ação de microorganismos, utilizando técnicas como secagem, cozimento, esterilização e fermentação - esta última considerada relevante por sustentar até contemporaneamente o conhecimento tradicional (KWON, 2017).

Alimentos artesanais têm sido vistos como fortemente relacionados aos contextos ecológicos da sua produção - o termo "ecologicamente incorporado" descreve os alimentos cujas características expressam condições socioambientais locais de sua produção, a relação de reforço mútuo entre alimentos e bebidas, suas ecologias locais e as práticas socioculturais de sua produção; os processos naturais são trazidos de volta ao cultivo e à produção, tornando sinal de valor a diversidade geográfica e temporal (KRZYWOSZYNSKA, 2015).

Neste contexto, a relação entre produção e consumo não está baseada na satisfação de expectativas pré-existentes e na fabricação de sabores, mas na introdução de novos hábitos e sensações, que podem no futuro contribuir com a produção de alimentos de forma mais ecológica e socialmente justa - atualmente, a maior parte do sistema agroalimentar ainda se dedica ao alimento global, de capital centralizado, agricultura extrativa e padronização de produtos (CAROLAN, 2011).

Em relação ao setor vinícola, observa-se o crescente interesse na produção "artesanal" e "natural"; são vinhos encontrados em feiras, adegas, restaurantes e bares especializados; diretamente com o produtor, por meio do enoturismo; e mesmo no mercado convencional e e-commerce. Estes promovem um retorno às práticas tradicionais de vinificação, utilizando agricultura orgânica ou biodinâmica, evitando métodos e ferramentas enológicas modernas para ampliar o efeito do terroir sobre as qualidades do vinho - suas características variam a cada ano, podendo exibir gostos e aromas considerados incomuns para a região e variedade (em relação à produção convencional) e apresentar aos consumidores materiais inesperados, como sedimentos de levedura ou tartaratos cristalizados. Assim, demandam uma compreensão do consumo e do gosto como atividade relacional e reflexiva (KRZYWOSZYNSKA, 2015).

$\mathrm{Na}$ vinificação convencional o processo de produção do vinho inicia-se com a colheita, recepção das uvas, esmagamento e desengace, fermentação, afinamento, maturação do vinho, filtragem, engarrafamento e rotulagem, envelhecimento (vinhos de guarda), análises do vinho e resíduos. São utilizadas cepas comerciais de levedura Saccharomyces cerevisiae que possuem atributos muito comuns, levando à produção de vinhos com qualidades padronizadas e sem características metabólicas necessárias para compor um perfil aromático de maior complexidade (APONTE, BLAIOTTA, 2016). Além disso, a enologia moderna utiliza substâncias como o bissulfito de amônio, metabissulfito de potássio, quitosano e fosfato de diamônio para controle na fermentação; sílica, bentonite, caolim, carvão ativado, caseinato de potássio, gelatina, albumina de ovo e de sangue e enzimas para clarificação; ácidos cítrico, málico, láctico, tartárico e bicarbonato de potássio para correção de acidez, entre outros tipos de correção visando padronizar o produto e atender as demandas de mercado (ENARTIS, 2018).

O próprio conceito de terroir se opõe a esta uniformização: o estabelecimento de Indicações Geográficas, por exemplo, é uma forma de reconhecer e valorizar a diversidade que compõe o setor vitivinícola, ela indica a origem dos produtos incorporando ativos imateriais, como reputação, fatores ambientais e humanos, traduzindo a identidade e cultura de um espaço geográfico - nestes casos, cabem às práticas sustentáveis potencializar a tipicidade, gerando produtos mais originais (FLORES, 2015).

\subsection{Ecoenogastronomia}


A possibilidade real de uma crise de produção e distribuição alimentar no contexto da finitude dos recursos naturais motiva o questionamento da sociedade em relação à suas escolhas alimentares (RUBIM, 2013). Em estudo aplicado nos Estados Unidos, Taylor, Barber e Deale (2010) identificaram que consumidores acreditam que vinícolas não protegem o meio ambiente local suficientemente e indicam que destinos turísticos, em especial regiões vinícolas, precisam considerar o impacto na comunidade local.

O futuro da produção vitivinícola depende da gestão sustentável de toda sua cadeia de abastecimento, da adoção de um padrão de desenvolvimento que respeite o meio ambiente, seja socialmente justo e economicamente eficaz. Nos últimos anos observou-se um aumento no número de iniciativas que promovem a qualidade de vida para os viticultores e trabalhadores do campo em geral, bem como a criação e partilha de valor do território que envolve os seus habitantes e a conservação das tradições culturais - trata-se de uma dimensão do empreendedorismo sustentável associada a um comportamento ético, que conecta economia, sociedade e meio ambiente (SCHIMMENTI et al., 2016).

A avaliação de questões ambientais, como qualidade da água ou poluição, costuma ser mais objetiva, enquanto as questões sociais e territoriais demandam análise qualitativa, muitas vezes baseadas em conceitos subjetivos e de difícil mensuração. É inegável que as dimensões sociais e ambientais estão intimamente relacionadas e a sustentabilidade também deve fomentar as condições para reprodução da identidade, principalmente no setor vinícola - o diálogo cultural com os arranjos e conservação da diversidade em termos de patrimônio, história e cultura é fundamental, pois os aspectos imateriais desempenham papel importante em termos de tradição e outros valores (FLORES, 2014).

Montanari (2008, p. 15) aponta que, sendo a alimentação uma atividade comum e vital, por diversas vezes é considerada meramente biológica, mas "os valores de base do sistema alimentar não se definem em termos de 'naturalidade', mas como resultado e representação de processos culturais que preveem a domesticação, a transformação, a reinterpretação da natureza". Em síntese, o autor considera que o que se entende por comida possui dimensão cultural, quando produzida, preparada e consumida. O território é referência absoluta nas escolhas alimentares, o comer geográfico exprime a cultura por meio do alimento, das receitas, da cozinha.

A International Organization of Vine and Wine (2016) considera que o respeito pela cultura e pela história da região são partes da sustentabilidade na produção vitivinícola; neste sentido, o termo ecoenogastronomia propõe-se a englobar as distintas dimensões envolvidas nesta atividade, promovendo a união entre "a ética e o prazer da alimentação, apoiando um modelo de agricultura menos intensivo, mais saudável, sustentável e que valorize o conhecimento de comunidades locais". O termo ecogastronomia surge do movimento Slow Food, organização mundial sem fins lucrativos, fundada em 1986 na Itália, com o objetivo de restituir ao alimento sua dignidade cultural, comprometendo-se a salvaguardar alimentos, matéria-prima e métodos tradicionais de cultivo e transformação dos alimentos. O Slow Food valoriza a pequena escala, a biocultura local e o respeito aos ritmos humanos naturais, lentos. Atualmente está presente em mais de cento e sessenta países e conta com cerca de cem mil membros (SLOW FOOD BRASIL, 2018, não p.).

A ecoenogastronomia está centrada em três valores, como mencionado - o alimento bom, justo e limpo - que se desdobram em fatores objetivos e subjetivos. O alimento bom envolve o sabor sensorial (alinhado às preferências individuais), e ao saber cultural (alinhado à história coletiva). O alimento limpo é definido como aquele que possui processo não poluente, com significado de um serviço ambiental, isto é: sustentável do ponto de vista ecológico - capaz de promover bem-estar e criar condições para a produção do alimento bom. O alimento justo está relacionado à justiça social, ao respeito aos trabalhadores, seus conhecimentos e à necessidade de serem 
recompensados adequadamente, ou seja, sustentável do ponto de vista econômico e social (MONTANARI, 2008; OLIVEIRA, 2013; SLOW FOOD, 2018).

O termo ecoenogastronomia é eventualmente encontrado nos documentos do movimento Slow Food, na literatura e é evidenciado neste artigo para efeito pedagógico, reafirmando o caráter alimentar do vinho.

\section{Resultados}

A Serra Gaúcha, localizada no Rio Grande do Sul, é composta pelas cidades: Antônio Prado, Barão, Bento Gonçalves, Carlos Barbosa, Caxias do Sul, Cotiporã, Farroupilha, Flores da Cunha, Garibaldi, Guaporé, Monte Belo do Sul, Nova Alvorada, Nova Araçá, Nova Bassano, Nova Pádua, Nova Prata, Nova Roma do Sul, Protásio Alves, Santa Tereza, Santo Antônio da Palma, São Marcos, Serafina Corrêa, Veranópolis, Vila Flores e Vista Alegre do Prata.

A região é de colonização italiana, polonesa e alemã, principalmente a primeira, que se iniciou em 1875 em Nova Milano, atual Farroupilha, estabelecendo colônias em diversas cidades. A atividade de vitivinicultura foi importante para a fixação da cultura italiana e o desenvolvimento econômico da Serra Gaúcha. Mediante o crescimento das exportações, foi entre 1910 e 1920 que os "velhos hábitos" foram substituídos por instruções e procedimentos técnicos, orientados ao atendimento das demandas de mercado; na época foi aprovada a primeira legislação envolvendo a produção de vinhos (CAVAGNOLLI, 1989). Frosi ${ }^{6}$ e Mioranza (1975 apud CAVAGNOLLI, 1989, p. 119) resgatam afirmação da época a respeito da divisão entre o colono viticultor e o comerciante vinicultor:

Ou o colono addiciona assucar ao mósto em quantidade sufficiente a produzir aquella porcentagem alccolica ou não the será permittido vinificar, devendo neste caso vender a uva que produzir às cantinas que trabalhem segundo a exigencia technica indispensável ã normalidade do producto e consoante as prescripções estabelecidas pela Repartição de hygiene do Estado (sic).

César (2016) observa que os valores memoriais do processo de assentamento do imigrante italiano estão presentes nos roteiros turísticos-culturais da Serra Gaúcha, com a recuperação de antigas estradas, formando um eixo sociocultural distribuído em comunidades agrícolas familiares organizadas em minifúndios.

\begin{abstract}
Esta condição, comumente é observada no imaginário dos seus moradores atuais, que muitas vezes preferem reforçar as raízes dos seus antepassados. Há décadas, a região tem como referencial turístico, o cultural. A atividade utiliza como recurso o processo de transposição de valores identitários europeus, associando-os a cultura da península itálica, através da gastronomia, arquitetura, entre outras características do cotidiano local (César, 2016, p. 417).
\end{abstract}

Trata-se da maior e mais importante região vinícola do país, somente a Serra Gaúcha produz cerca de $85 \%$ de todo o vinho nacional. Caracterizada pelo solo basáltico e o clima temperado e úmido, com noites amenas, a região possui quatro áreas de produção enológica certificadas do país: o Vale dos Vinhedos, entre as cidades de Bento Gonçalves, Garibaldi e Monte Belo do Sul, que possui Denominação de Origem, os municípios de Pinto Bandeira e Monte Belo do Sul, que possuem Indicação de Procedência e a região dos Altos Montes, que abrange as cidades de Flores da Cunha e Nova Pádua. As Denominações Geográficas são obtidas mediante o atendimento de requisitos, determinando tipos de uva, técnicas adotadas, entre outros (IBRAVIN, 2018).

Oficialmente, existem mais de mil vinícolas no país, a maioria em pequenas propriedades (média de 2 hectares por família), mas apenas cerca de cento e cinquenta se dedicam aos vinhos finos (IBRAVIN, 2018). Há vinícolas artesanais que não se enquadram na legislação vigente, não sendo contabilizadas nestes números; para se enquadrar na Lei do Vinho Colonial

\footnotetext{
${ }^{6}$ FROSI, V. M.; MIORANZA, C. Imigração italiana no nordeste do RS. Caxias do Sul, ÜCS/Movimento, 1975.
} 
é necessário ser produtor da agricultura familiar, fabricar até vinte mil litros de vinho ao ano no próprio imóvel rural, cultivar $100 \%$ das uvas utilizadas na elaboração da bebida e ter faturamento anual de até $\mathrm{R}$ \$ 274 mil. As dificuldades de adequação envolvem diversos fatores, como a falta de recursos para atender as normas construtivas sanitárias, contratar um responsável técnico, entre outros.

\subsection{Localização das vinícolas artesanais}

Figura 1: Localização das vinícolas artesanais na Serra Gaúcha



Fonte: autores, 2018.

Foram identificadas oito vinícolas artesanais nos municípios de Bento Gonçalves (1), Monte Belo do Sul (2), Pinto Bandeira (2), Garibaldi (2) e Nova Pádua (1). Para a análise, foram incluídas vinícolas fora dos limites da Serra Gaúcha pela próxima relação com o grupo de vinhateiros artesanais, em Colinas (1), Porto Alegre (2) e Caçapava do Sul (1).

\subsection{Práticas de cultivo e vinificação}

\subsubsection{Produção sustentável, orgânica e} biodinâmica
Utilizando a categoria "autoavaliação" proposta por Flores (2015), foram identificadas práticas sustentáveis, orgânicas e biodinâmicas no manejo das videiras de vinícolas artesanais. Os produtores procuram evidenciar a importância de uma produção mais ecológica, principalmente pelo impacto na qualidade das uvas e, posteriormente, do vinho.

Parte dos produtores estão organizados em grupos de certificação orgânica, como Ecocert, e certificação orgânica participativa, como a Rede Ecovida. Não há produções certificadas pela Demeter (biodinâmica), mas há expectativa de que estabeleçam parcerias com certificadoras locais para este processo. As barreiras culturais também afetam vinhateiros jovens, que desejam fazer a transição do vinhedo para orgânico ou biodinâmico, mas encontram resistência da família.

Há casos onde o produtor realiza o manejo sustentável do solo e da vinha, mas têm que lidar com empecilhos, como quando também fornece uvas para grandes empresas e estas fazem a orientação do uso de alguns insumos. Em outros casos, alguns recorrem ao uso destas substâncias em situações emergenciais, para não perder o vinhedo ou a produção do ano.

Como a maior parte dos vinhateiros artesanais utiliza técnicas de vinificação livre de substâncias sintéticas, este processo fica sensivelmente mais suscetível a ação de bactérias indesejadas; na vinificação natural há pouco uso ou ausência de sulfito adicionado, que é responsável por selecionar leveduras ideais para a fermentação do mosto, gerando aromas e sabores alinhados aos padrões comerciais e de consumo global. Para minimizar estes riscos e extrair o melhor da uva, há rigoroso controle e dedicação ao manejo do solo e das videiras; produtores orgânicos tem realizado a transição para agricultura biodinâmica, pois reconhecem os resultados positivos no produto final, destacando-se que nem todos entendem a biodinâmica em seu holismo, mas a adotam instrumentalmente.

\subsubsection{Resgate de variedades}


Nas últimas décadas, a produção de vinhos do Novo Mundo ateve-se a cultivar majoritariamente as varietais Chardonnay, Merlot e Cabernet Sauvignon. Indiferentemente, o Brasil acompanhou as tendências de mercado e priorizou a produção destas castas, incluindo a Pinot Noir e Riesling Itálico, amplamente utilizadas na fabricação de espumantes. Variedades como a Cabernet Franc foram protagonistas na história do vinho brasileiro, mas hoje são exceções, como a Trebbiano, Teroldego, Barbera e Peverella.

O projeto "Arca do Gosto" do movimento Slow Food explica que a uva Peverella foi a primeira variedade branca de Vitis vinífera a desembarcar no Brasil com os imigrantes italianos no final do século XIX. Produzida desde a década de 20, sendo nos anos 40 a principal variedade vinífera branca cultivada no Rio Grande do Sul, manteve-se em posição de destaque até a década de 70 , quando foi praticamente extinta pela demanda de mercado por outras varietais (SLOW FOOD, 2018).

No levantamento realizado foi possível observar que muitos vinhateiros artesanais voltaram a cultivar estas uvas, mesmo grandes vinícolas. No caso da Peverella, são as pequenas produções que recuperam a variedade, tendo como resultado espumantes, vinhos brancos e brancos de maceração ímpares. Apesar de sua importância histórica, somente a Indicação de Procedência de Pinto Bandeira permite o cultivo desta uva, sendo a mais abrangente em número de castas.

Outro aspecto interessante é que os vinhateiros nem sempre se atém a vinificar suas próprias uvas, ocorrendo vendas entre os produtores para elaboração de assemblagem, por exemplo.

As castas Isabel (híbrida de Vitis vinífera e Vitis labrusca) e Borgonha ou Herbemont (Vitis bourquina), comumente utilizadas para sucos, vinhos de mesa, destilação e associadas à vinhos de baixa qualidade, recebem atenção dos produtores artesanais, que as vinificam com os mesmos preceitos observados na produção de vinhos finos. Com isso, as

\footnotetext{
7 Conceito que se refere a uma área em que se desenvolve o conhecimento coletivo das interações entre o ambiente físico e biológico identificável e as práticas vitivinícolas aplicadas, fornecendo características
}

colocam em posição de destaque, evidenciando o potencial de culturas mais adaptadas ao solo e clima local, utilizadas por seus ancestrais.

\subsubsection{Vinificação de baixa intervenção e métodos ancestrais}

Diferentemente do imaginário que associa as vinícolas artesanais ao vinho colonial de baixa qualidade, foram identificadas diversas iniciativas que optam por produzir vinhos finos, destinados ao próprio consumo e a um mercado alternativo específico e com valor agregado. A comercialização é realizada por contato direto e em feiras especializadas, sendo poucos os que possuem os requisitos necessários para o comércio em lojas físicas e e-commerce. Apesar disso, estão presentes em redes sociais e costumam atuar na divulgação do vinho sustentável, vinho natural, vinho livre, vinho vivo, dentre outras autodenominações.

$\mathrm{Na}$ cantina de muitas vinícolas artesanais vinifica-se sem 0 uso de leveduras exógenas importadas e outros produtos enológicos na produção deste tipo de vinho, como os imigrantes italianos faziam no começo do século, com mínima intervenção. Nesse tipo de vinificação, classificada por vinhateiros artesanais brasileiros como vinificação natural, "o vinho se faz sozinho", mas requer o cuidado de obter uvas sãs para a elaboração, evitando a proliferação de bactérias acéticas, responsáveis pelo sabor e odor de vinagre. Na vinificação natural são preservados os aspectos naturais da elaboração do vinho, refletindo a safra e o terroir ${ }^{7}$, não há chaptalização (adição de açúcar de cana para aumentar a graduação alcoólica) ou adição de produtos químicos para corrigir aromas, sabores, acidez, realizar clarificação, etc.

No processo de vinificação de vinhos brancos foi identificada uma prática pouco usual nas grandes vinícolas brasileiras, o uso do contato pelicular (cascas) para a produção de vinho branco de

distintivas para os produtos oriundos dessa área. Terroir inclui solo específico, topografia, clima, características da paisagem e características da biodiversidade. 
maceração, também conhecido como vinho laranja ou âmbar. Trata-se de uma prática ancestral, quase sempre associada aos processos de vinificação natural, pois utiliza as leveduras contidas na casca da uva para induzir o processo de fermentação espontânea.

$\mathrm{Na}$ produção de espumantes, o método tradicional ou champenoise é unanimemente utilizado, podendo incluir também o método ancestral (com a segunda fermentação na garrafa) e, mais recentemente, o pétillant-naturel, que significa espumante natural, onde não há adição de licor de tirage ou de expedição (vinho base com açúcar). Em grandes vinícolas são adotadas técnicas como 0 método Charmat e Asti (com fermentação nos tanques de inox), além do método tradicional.

\section{Discussão}

Ao analisar a literatura sobre o setor vinícola, é possível verificar que a sustentabilidade muitas vezes está limitada a uma abordagem ambiental ou de pegada - de carbono, hídrica, ecológica - deixando de incluir importantes aspectos, como os sociais e culturais. As práticas estão voltadas majoritariamente à viticultura e não à enologia, o que no Brasil pode ser justificado pelo estabelecimento tardio do vinho enquanto cultura difundida, ocorrendo na mesma época em que o setor se encontrava na etapa de industrialização e houve o advento da enologia moderna.

Até então, a produção de vinhos envolvia o manejo da vinha e a vinificação com base em conhecimentos ancestrais e, por fim, o consumo e a venda da produção excedente. Práticas como a troca de mudas e sementes eram comuns entre os imigrantes italianos na Serra Gaúcha, sendo a adaptabilidade da videira ao solo e clima fator principal para seu cultivo. A gestão dos resíduos era feita na propriedade, servindo também de base para outros produtos. Com a necessidade de atender padrões de mercado, muitos colonos deixaram de comercializar seus vinhos, passando a vender as uvas para as grandes indústrias.

Atualmente, além das grandes produções, é possível encontrar pequenos produtores de vinho artesanal na Serra Gaúcha, realizando uma resistência pacífica aos processos de homogeneização cultural alimentar. Estes adotam práticas que se estabelecem como bases de uma sustentabilidade vinícola, como a agricultura sustentável, orgânica ou biodinâmica. Frequentemente realizam primeiramente a agricultura sustentável para então fazer a transição para a orgânica, podendo adotar a agricultura biodinâmica. É interessante observar que a produção biodinâmica permite certa independência, pois o agricultor é responsável por produzir seus insumos com os recursos de sua propriedade, mas por ter origem estrangeira, ainda há limitações, indicando a necessidade de desenvolver a agricultura biodinâmica brasileira adaptada à ecologia local.

$\mathrm{Na}$ Serra Gaúcha o cultivo do vinhedo tradicionalmente é uma prática familiar e o vinho é parte indispensável da refeição: para o agricultor o vinho é considerado alimento. O distanciamento do processo de elaboração artesanal do vinho o desassociou da cultura alimentar, na qual o consumidor se limita a observar apenas a ponta da cadeia produtiva, o que não lhe dá informações suficientes dos aspectos culturais, ambientais e mesmo nutricionais do vinho.

As vinícolas identificadas neste artigo utilizam práticas que aliam sustentabilidade e, ainda que não propositalmente, um "resgate biocultural" do vinho. Neste aspecto, as produções artesanais realizam o manejo sustentável da vinha, recuperam castas não privilegiadas pela indústria e utilizam técnicas ancestrais de vinificação, visando a mínima intervenção. Apesar de ter a qualidade dos vinhos reconhecida por experts, é notável que este tipo de produção não representa uma concorrência ou ameaça à indústria do vinho - que também passa por um processo de adaptação às exigências do consumidor consciente - mas reivindica o direito de 
ocupar lacunas que garantam sua existência e resguardem o patrimônio cultural do vinho.

Para além disso, é necessário também reconhecer que, em seu contexto territorial e cultural, o vinho artesanal é considerado alimento e, assim sendo, deve-se compreender de que forma é produzido, sustentando o emergente e necessário consumo consciente, como a ecoenogastronomia promove. Nesta perspectiva, observam-se pontos de congruência entre a realidade observada e este conceito: das iniciativas identificadas, todas realizam um esforço para tornar a produção do vinho mais sustentável - ambiental, social e economicamente - e dedicam-se a resgatar a cultura do vinho artesanal. Em outras palavras, buscam oferecer à sua família e seus consumidores um alimento bom, limpo e justo. A pequena escala, a importância da biocultura local e o respeito aos ritmos naturais são partes intrínsecas deste tipo de produção de alimentos ecologicamente incorporados, como nomeia Krzywoszynska (2015).

A autora enfatiza ainda que há que se reconhecer as ecologias locais envolvidas na produção de alimentos, como é a ecologia do vinho artesanal, que envolve a família vitivinicultora, sua propriedade e o consumidor, prezando pelas gerações futuras na preservação de toda cadeia, do vinhedo à mesa.

\section{Considerações finais}

Retomando o objetivo inicial deste trabalho de analisar a relação entre sustentabilidade e resgate cultural na produção de vinhos no Brasil, a partir da perspectiva da ecogastronomia, foi possível confirmar a estrita relação entre práticas de sustentabilidade e práticas de resgate cultural na produção de vinhos artesanais na Serra Gaúcha. Estas experiências atuam na promoção de um "vinho bom, justo e limpo", ecologicamente incorporado e ancorado nas raízes da cultura local.

As iniciativas de pequena escala, muitas vezes não regularizadas nos órgãos oficiais pela dificuldade de adequação, buscam organização, partilham conhecimento e almejam certificações; não pretendem substituir a indústria do vinho, mas não deixam de buscar aprimoramento das práticas artesanais herdadas da ancestralidade. Além disso, conseguem captar e vivenciar a preservação: dos cultivares, da cultura e principalmente de suas próprias famílias, pois a escolha pela agricultura e vinificação de baixa intervenção é reforçada pelo desejo de manter seus entes sãos, uma vez que casos de patologias causadas pelo uso indiscriminado de insumos agrícolas são recorrentes na Região Sul.

A imersão biocultural é evidenciada no resgate do cultivo e da vinificação de castas como a Peverella, entre outras varietais que possuem relevância histórica por terem sido cultivadas pioneiramente pelos imigrantes italianos, além de apresentarem melhor adaptação ao clima e solo, necessitando de menor intervenção no manejo das videiras - neste sentido, também são respeitados os ciclos naturais, com a atenta dedicação da família vitivinicultora, motivados em evidenciar o terroir e entregar um "vinho feito por si só".

A ecoenogastronomia, assim, representa elemento significativo para o que se denomina por Bem Viver, segundo Sampaio et al. (2017), a partir da perspectiva da relação sinérgica entre homem e natureza, no sentido ecocêntrico, na qual não coisifica o meio ambiente, como mero recurso produtivo (neste caso insumo), e ao mesmo tempo possui denotação cultural, dando-Ihe identidade ou nominação territorial.

Por fim, é preciso reconhecer que o tema das produções artesanais e da sustentabilidade é fértil e não se encerra neste estudo, podendo ser analisado em diversas abordagens, como a inserção de mercado dos vinhos artesanais, a adaptação das práticas biodinâmicas à ecologia local, análises comparativas de qualidade de vida entre estes produtores e vitivinicultores convencionais e mesmo o olhar de outros conceitos que não a ecoenogastronomia, apesar desta demonstrar capacidade de englobar suas diversas dimensões.

\section{Referências}


APONTE, M.; BLAIOTTA, G. Selection of an autochthonous Saccharomyces cerevisiae strain for the vinification of "Moscato di Saracena", a southern Italy (Calabria Region) passito wine. Food Microbiology, v. 54, p. 30-39, 2016,

BARBER, N.; TAYLOR, C.; STRICK, S. Wine consumers' environmental knowledge and attitudes: Influence on willingness to purchase. International Journal of Wine Research, p. 59-72, 2009.

CAROLAN, M. S. Embodied Food Politics. Farnham: Ashgate, 2011

CAVAGNOLLI, A. Os parceiros do vinho: a vitivinicultura em Caxias do Sul (1911-1936). Dissertação (Mestrado em História do Brasil), Universidade Federal do Paraná, Curitiba, 1989.

CÉSAR, P. A. B. Roteiros turístico-culturais na Serra Gaúcha (RS-Brasil): escolha e formação dos percursos e seu apelo histórico memorial. Revista Brasileira de Pesquisa em Turismo, São Paulo, v. 10, n. 3, p. 416434, 2016.

CHRIST, K. L.; BURRITT, R. L. Critical environmental concerns in wine production: an integrative review. Journal of Cleaner Production, n. 53, p. 232-242, 2013.

ENARTIS. Catálogo de produtos. Página da internet, $2018 . \quad$ Disponível em: $<$ http://www.enartis.com.pt/index.cfm>. Acesso em: 02 out. 2018.

FLORES, S. S. Terroir and sustainability: the role of terroir in sustainable wine standards. In: Proceedings of XXI Enometrics Conference. VDQS, Lyon, France, 2014.

FLORES, S. S. Vitivinicultura sustentável no contexto do Brasil: uma proposta de abordagem. Tese (Doutorado em Geografia), Universidade Federal do Rio Grande do Sul e Université de Bourgogne, 2015.

FLORES, S. S. What is sustainability in the wine world? A cross-country analysis of wine sustainability frameworks. Journal of Cleaner Production, n. 172, p. 2301-2312, 2018.

GÓES, J. A. W. Fast-food - um estudo sobre a globalização alimentar. Salvador: EDUFBA, 2010.

HARVEY, D. A arte de lucrar: globalização, monopólio e exportação de cultura. In: MORAES, D. Por uma outra comunicação: mídia, mundialização cultural e poder. Rio de Janeiro: Record, 2003.

INTERNATIONAL ORGANIZATION OF VINE AND WINE. Resolution CST 1/2004. Disponível em: $<$ http://www.oiv.int/public/medias/2074/cst-1-2004en.pdf>. Acesso em: 02 out. 2018.

INTERNATIONAL ORGANIZATION OF VINE AND WINE. Resolution OIV-CST 518-2016. Disponível em: $<$ http://www.oiv.int/public/medias/5766/oiv-cst-5182016-en.pdf>. Acesso em: 10 out. 2018.
KRZYWOSZYNSKA, A. Wine is not Coca-Cola: marketization and taste in alternative food networks. Agriculture and Human Values, v. 32, n. 3, p. 491-503, 2015.

KWON, D. Y. Ethnic foods and globalization. Journal of Ethnic Foods, v. 4, p. 1-2, 2017.

MARIANI, A.; VASTOLA, A. Sustainable winegrowing: current perspectives. International Journal of Wine Research, n. 7, p. 37-48, 2015.

MERLI, R.; PREZIOSI, M.; ACAMPORA, A. Sustainability experiences in the wine sector: toward the development of an international indicators system. Journal of Cleaner Production, n. 172, p. 3791-3805, 2018.

MONTANARI, M. Comida como cultura, Editora Senac, São Paulo, 2008.

MONTELLA, M. M. Wine tourism and sustainability: a review. Sustainability, n. 9, v. 113, p. 1-11, 2017.

OLIVEIRA, D. C. O slow food e uma nova cultura alimentar. Sociedade e Cultura, v. 16, n. 1, p. 205-207, 2013.

POMARICI, E.; VECCHIO, R. Millennial generation attitudes to sustainable wine: an exploratory study on Italian consumers. Journal of Cleaner Production, n. 66, p. 537-545, 2014.

RIBEIRO, H.; JAIME, P. C.; VENTURA, D. Alimentação e sustentabilidade. Estudos Avançados, São Paulo, v. 31, n. 89, p. 185-198, 2017.

RUBIM, R. E. A Ecogastronomia nos Cursos Superiores de Gastronomia do Estado de São Paulo: Conceitos, Aplicações e o Cenário Observado. Rosa dos Ventos, v. 5, n. 2, p. 280-292, 2013.

SAMPAIO, C. A. C.; PARKS, C.; MANTOVANELLI JR, O.; QUINLAN, R.; ALCÂNTARA, L. Bem viver e ecossocioeconomia: entre subjetividade e o bem comum. Saúde e Sociedade, v. 26 n. 1, p. 40-50, 2017.

SANTOS, C. R. A. dos. A comida como lugar de história: As dimensões do gosto. Questões \& Debates, Curitiba, n. 54, p. 103-124, 2011.

SCHÄUFELE, I.; HAMM, U. Organic wine purchase behaviour in Germany: Exploring the attitudebehaviour-gap with data from a household panel. Food Quality and Preference, v. 63, p. 1-11, 2018.

SCHIMMENTI, E.; MIGLIORI, G. FRANCO, C. P.; BORSELLINO, $\mathrm{V}$. Is there sustainable entrepreneurship in the wine industry? Exploring Sicilian wineries participating in the SOStain program. Wine Economics and Policy, n. 5, p. 14-23, 2016. 
SLOW FOOD BRASIL, Página da internet. Disponível em: <https://www.slowfoodbrasil.com/>. Acesso em: 18 out. 2018 .

SOUZA, M. C. M.; OTANI, M. N.; VERDI, A. R. Valorização da cultura italiana e o consumo de vinho artesanal. Informações Econômicas, São Paulo, v. 40, n. 6 , p. 56-67, 2010.

SZOLNOKI, G. A cross-national comparison of sustainability in the wine industry. Journal of Cleaner Production, n. 53, p. 543-251, 2013.

TAYLOR, C.; BARBER, N.; DEALE, C. Environmental attitudes towards wine tourism. International Journal of Wine Research, p. 13-26, 2010.

TERUCHKIN, S. R. U. As estratégias empresariais para os vinhos finos no Brasil e no Uruguai: uma análise comparada. Tese (Programa de PósGraduação em Administração), Universidade Federal do Rio Grande do Sul, 2003. Disponível em: $<$ https://lume.ufrgs.br/bitstream/handle/10183/4066/00 0407153. pdf? sequence $=1$ \&isAllowed=y>. Acesso em: 05 nov. 2018. 